\title{
PERENCANAAN ARSITEKTUR SISTEM INFORMASI DINAS PARIWISATA MENGGUNAKAN MODEL EAP
}

\author{
Rintho Rante Rerung \\ Manajemen Informatika \\ Politeknik Perdana Mandiri Purwakarta \\ Email: rintho@rantererung.com
}

\begin{abstract}
ABSTRAK
Dinas Kebudayaan dan Pariwisata Tana Toraja merupakan salah satu lembaga teknis daerah dengan fungsi utama mengembangkan pariwisata untuk memperoleh manfaat ekonomi dan sosial dari kegiatan pariwisata. Sistem informasi berbasis teknologi informasi perlu direncanakan agar dapat memberikan gambaran sistem informasi yang diperlukan untuk mendukung proses bisnis dinas. Perencanaan ini menggunakan model EAP. Model EAP akan mendefinisikan kebutuhan bisnis dan arsitekturnya. Dari hasil penelitian, maka ditemukan bahwa aplikasi yang diperlukan dalam sistem informasi adalah website pariwisata, aplikasi keuangan, aplikasi $H R D$ dan aplikasi pengawasan dan evaluasi.
\end{abstract}

Kata kunci: arsitektur enterprise, sistem informasi, EAP, pariwisata.

\section{ABSTRACT}

Department of Culture and Tourism of Tana Toraja is one of the technical agencies in the Government of Tana Toraja. One of the main functions of this institute are to develop tourism to get economic and social benefits from tourism activities. An enterprise information systems based on information technology should be planned to provide an overview of information systems to support business process services. The planning is used EAP models. EAP models will define the business requirements and the architecture. From the research mentioned above, it has found that the application required in the information system is tourism website, financial application, human resources department (HRD) application, and Controlling and Evaluation application.

Keywords: enterprise architecture, information system, EAP, tourism.

\section{PENDAHULUAN}

\subsection{Latar Belakang}

Sektor pariwisata telah menjadi bagian kegiatan perekonomian dan telah menjadi andalan potensial bahkan prioritas pengembangan bagi sejumlah negara, terutama bagi negara berkembang seperti Indonesia. Berdasarkan persepsi pelaku wisata dan hasil observasi lapangan Kajian Penurunan Jumlah Wisatawan di Tana Toraja ditemukan bahwa kondisi pariwisata Tana Toraja saat ini sudah berada pada titik kritis[3]. Sesuai dengan siklus hidup pariwisata model Butler dan Miossec, maka pariwisata Tana Toraja berada pada tahap penurunan (decline phase). Salah satu penyebabnya adalah sistem pengelolaan data yang buruk hingga tidak tersedianya informasi yang memadai sehingga wisatawan tidak termotivasi untuk berkunjung ke Tana Toraja. Dengan penurunan tersebut maka dapat dipastikan bawah pendapatan pemerintah daerah Tana Toraja dari sektor pariwisata mengalami penurunan. Melihat dari kondisi tersebut maka perlu merencanakan sebuah sistem informasi berbasis teknologi informasi (TI) untuk dapat membantu baik pemerintah selaku pengelolah maupun calon wisatawan sebagai pihak yang akan mengakses infomasi tersebut.

\subsection{Rumusan Masalah} adalah:

Berdasarkan latar belakang yang telah diuraikan diatas maka rumusan masalah dalam penelitian ini

1) Bagaimana merencanakan sistem informasi Dinas Pariwisata berbasis TI yang dapat mendukung visi dan misi Dinas Kebudayaan dan Pariwisata Tana Toraja;

2) Bagaimana merencanakan sistem informasi Dinas Pariwisata berbasis TI agar sesuai dengan proses bisnis Dinas Kebudayaan dan Pariwisata Tana Toraja; 
3) Bagaimana merencanakan sistem informasi Dinas Kebudayaan dan Pariwisata Tana Toraja yang sesuai dengan perkembangan teknologi saat ini.

\subsection{Tujuan Penelitian}

Adapun tujuan dari penelitian ini adalah sebagai berikut:

1) Merencanakan arsitektur sistem informasi Dinas Pariwisata berbasis TI untuk mendukung visi dan misi Dinas Kebudayaan dan Pariwisata Tana Toraja;

2) Merencanakan arsitektur sistem informasi Dinas Pariwisata berbasis TI yang sesuai dengan proses bisnis Dinas Kebudayaan dan Pariwisata Tana Toraja;

3) Merencanakan arsitektur sistem informasi Dinas Pariwisata Tana Toraja berbasis TI yang sesuai dengan teknologi yang berkembang saat ini.

\subsection{Sistem Informasi}

Sistem informasi adalah suatu sistem di dalam suatu organisasi yang mempertemukan kebutuhan pengolahan transaksi harian, mendukung operasi, bersifat manajerial dan kegiatan strategi dari suatu organisasi dan menyediakan pihak luar tertentu dengan laporan-laporan yang diperlukan [2]. Sistem informasi juga didefinisikan sebagai cara dari orang-orang dan organisasi-organisasi memanfaatkan teknologi, mendapatkan, memproses, menyimpan, menggunakan, dan menyebar informasi. Sistem informasi merupakan bagian domain yang lebih luas dari pengembangan yang berkelanjutan dalam merespon inovasi teknologi serta interaksi yang mutual dengan kehidupan sosial secara keseluruhan[8]. Dari defenisi tersebut dapat dapat disimpulkan bahwa sistem infomasi adalah sistem dalam sebuah organisasi yang digunakan untuk mengelolah data atau informasi dengan memanfaatkan teknologi baik untuk kebutuhan internal maupun kebutuhan external.

\subsection{Rantai Nilai (Value Chain)}

Michael Porter menyatakan bahwa "setiap perusahaan merupakan kumpulan aktivitas yang dilakukan untuk merancang, menghasilkan, memasarkan, menyampaikan dan mendukung produk atau layanannya"[7]. Semua aktivitas ini dapat disajikan dalam bentuk value chain. Value chain hanya dapat dipahami dalam konteks unit bisnis. Kunci analisis value chain adalah memahami aktivitas di dalam institusi yang menciptakan manfaat kompetitif serta pengaturan aktivitas tersebut lebih baik dari institusi lain pada industri [9].

\subsection{Entity Relationship Diagram (ERD)}

Model diagram E-R adalah model diagram yang didasarkan pada sebuah persepsi dunia nyata yang terdiri dari obyek dasar yang disebut dengan entitas dan hubungannya diantara entitas tersebut [1]. Definisi ERD menurut Fatansyah dalam bukunya yang berjudul Basis Data, menyebutkan bahwa "Entity Relationship Diagram yaitu berisi komponen-komponen himpunan entitas dan himpunan relasi yang masing-masing dilengkapi dengan atribut-atribut yang merepresentasikan seluruh fakta dari dunia nyata”[1]. Simbol- Simbol ERD yang dapat kita gunakan adalah:

1) Entitas adalah objek yang dapat didefinisikan dalam lingkungan user, sesuatu yang penting bagi pemakai dalam konteks sistem yang akan dibuat. Sebagai contoh pelanggan, user dll.

2) Atribut adalah properti atau karakteristik yang dimiliki oleh suatu entitas dimana properti atau karakteristik itu bermakna atau berarti bagi organisasi atau perusahaan.

3) Relasi adalah hubungan antara suatu himpunan dengan himpunan entitas yang lainnya.

4) Arus Data adalah Simbol yang menunjukan arah dari arus data.

\subsection{Enterprise Architecture}

Arsitektur Enterprise merupakan cara untuk menggambarkan model operasional enterprise yang mencakup aspek perencanaan bisnis, operasional bisnis, otomasi, hingga infrastruktur teknologi informasi pendukungnya. Arsitektur Enterprise memiliki empat komponen utama yaitu arsitektur bisnis, arsitektur informasi (data), arsitektur teknologi dan arsitektur aplikasi. Arsitektur enterprise mempunyai arti penting bagi organisasi sebab salah satu hasilnya adalah keselarasan (alignment) antara teknologi informasi dan kebutuhan bisnis [4]. 


\subsection{Enterprise Architecture Planning}

Enterprise Architecture Planning adalah proses pendefinisian arsitektur dalam penggunaan informasi untuk mendukung bisnis dan rencana untuk mengimplementasikan arsitektur tersebut [5]. Enterprise Architecture Planning memiliki 7 (tujuh) komponen utama yang menunjukkan tahapan untuk menentukan dan merencanakan implementasi arsitektur sistem informasi. Tujuh komponen utama ini dikelompokkan menjadi 4 lapisan [5] seperti Gambar 1.

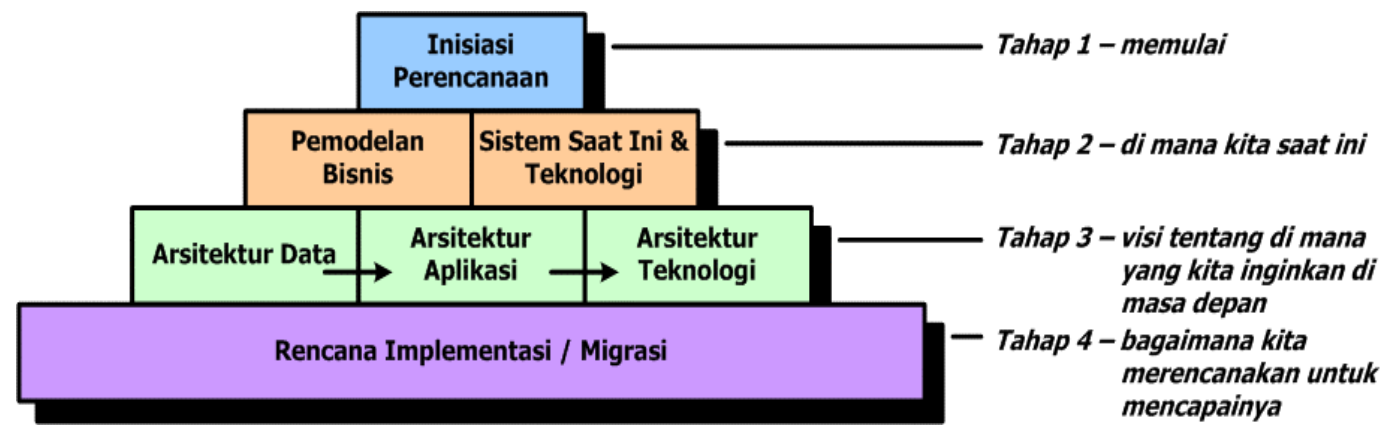

\section{Gambar 1. Komponen dan Lapisan $E A P[1]$}

Dari gambar di atas, dapat disimpulkan bahwa tahapan dan apa yang dihasilkan dari setiap tahapan EAP pada Tabel 1:

Tabel 1. Tahapan dan hasil dari $E A P$

\begin{tabular}{|c|c|c|}
\hline Lapisan & Tahapan & Hasil \\
\hline 1 & Inisiasi Perencanaan & $\begin{array}{l}\text { Ruang lingkup, sasaran, visi, penentuan metodologi } \\
\text { dan alat-alat yang akan digunakan, perencanaan tim, } \\
\text { presentasi, rencana kerja. }\end{array}$ \\
\hline \multirow[t]{3}{*}{2} & Pemodelan Bisnis & Struktur oragnisasi, model fungsi bisnis awal \\
\hline & Survey Perusahaan & Perlengkapan model bisnis fungsional \\
\hline & $\begin{array}{l}\text { Sistem dan teknologi } \\
\text { saat ini }\end{array}$ & Katalog sumber daya informasi (IRC), skema sistem \\
\hline \multirow[t]{3}{*}{3} & Arsitektur Data & $\begin{array}{l}\text { Pendefisian entitas, diagram } E R \text {, matriks entitas } \\
\text { terhadap fungsi, dokumen arsitektur data }\end{array}$ \\
\hline & Arsitektur Aplikasi & $\begin{array}{l}\text { Pendefinisian aplikasi-aplikasi, matriks aplikasi, } \\
\text { dokumen arsitektur aplikasi }\end{array}$ \\
\hline & Arsitektur Teknologi & Distribusi data/aplikasi, dokumen arsitektur aplikasi \\
\hline \multirow[t]{5}{*}{4} & Rencana & Urutan aplikasi/roadmap, rencana migrasi, faktor- \\
\hline & Implementasi & faktor sukses dan rekomendasi \\
\hline & Kesimpulan & Dokumen akhir, presentasi \\
\hline & Perencanaan & \\
\hline & $\begin{array}{l}\text { Transisi terhadap } \\
\text { implementasi }\end{array}$ & $\begin{array}{l}\text { Peningkatan organisasi, kebijakan-kebijakan, } \\
\text { standard, prosedur-prosedur, rencana terperinci }\end{array}$ \\
\hline
\end{tabular}

\subsection{Zachman Framework}

Langkah-langkah dalam EAP memberikan panduan praktis dalam membuat arsitektur dari dua baris dan tiga kolom pertama kerangka kerja Zachman [6]. Kerangka kerja Zachman merupakan kerangka kerja untuk memetakan hubungan antara komponen enterprise terhadap level arsitektur yang menjadi perhatian pihak-pihak yang berkepentingan dengan enterprise architecture. Hubungan antara kerangka kerja Zachman dan EAP adalah proses mendefinisikan dua level atas kerangka kerja Zachman. Sehingga jika dipetakan ke dalam kerangka kerja Zachman, EAP akan berada di baris pertama dan baris kedua yang merupakan perspektif perencana dan pemilik. Sedangkan aspek yang dibahas dalam $E A P$ berada pada tiga kolom dari kerangka kerja Zachman, yaitu meliputi data, fungsi dan jaringan dari arsitektur sistem informasi. 


\subsection{Four Stage Life Cycle Bussiness System Planning (BSP)}

Four Stage Life Cycle adalah tool yang digunakan untuk menemukan turunan dari fungsi bisnis yang terkait dengan produk/layanan yang diberikan oleh fungsi bisnis tersebut [9]. Four Stage Life Cycle pada $B S P$ digunakan pada tahap pendefinisian proses bisnis. Ada empat siklus yang digunakan [9], yaitu:

1) Requirements, Planning, Measurements And Control, merupakan tahap untuk menentukan berapa banyak produk/layanan yang dibutuhkan, rencana untuk mendapatkannya dan pengukuran serta kontrol yang digunakan.

2) Acquisition, merupakan tahap untuk mengembangkan produk/layanan atau untuk mendapatkan sumber daya yang akan dipergunakan untuk kegiatan pengembangan.

3) Stewardships, merupakan tahap untuk membentuk, mempertajam, memodifikasi atau merawat dukungan sumber daya dan untuk menyimpan atau menelusuri produk atau layanan.

4) Retirement, merupakan tahap keputusan akhir dari tanggung jawab organisasi untuk suatu produk atau layanan atau sinyal yang menyatakan akhir dari penggunaan suatu sumber (resource).

\subsection{Application Portofolio}

Sistem aplikasi dalam suatu organisasi apakah itu yang berkaitan dengan pengolahan data transaksi, sistem informasi manajemen dan sebagainya perlu untuk dirancanakan dan dikelola apa yang dapat diberikan setiap aplikasi tersebut terhadap usaha pencapaian tujuan bisnis organisasi, dengan mengikuti apa yang ada saat ini dan masa yang akan dating [9]. Application Portofolio Matrix dapat dilihat pada gambar 2 berikut ini.

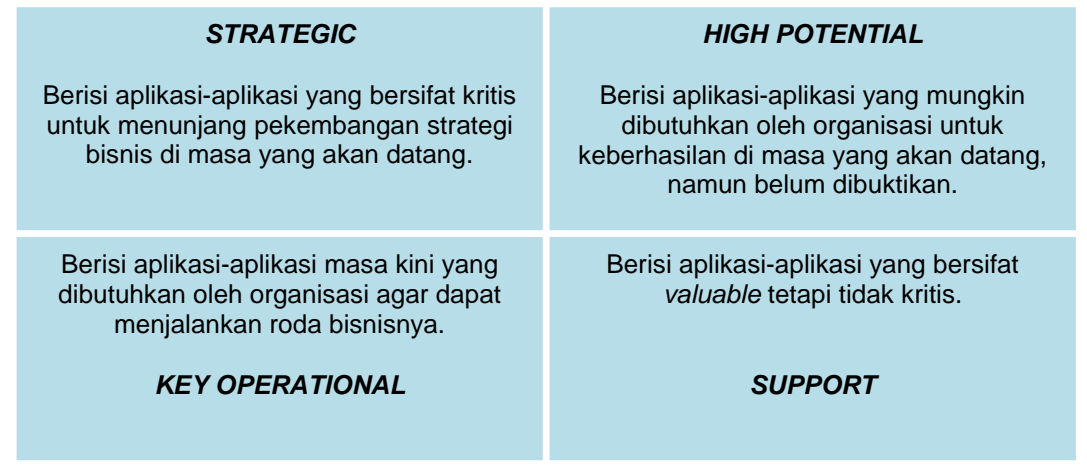

Gambar 2. Application Portfolio Matrix [9]

\subsection{Blueprint}

Blueprint adalah kerangka kerja terperinci (arsitektur) sebagai landasan dalam pembuatan kebijakan yang meliputi penetapan tujuan dan sasaran, penyusunan strategi, pelaksanaan program dan fokus kegiatan serta langkah-langkah atau implementasi yang harus dilaksanakan oleh setiap unit di lingkungan kerja. Blueprint IT mencakup tiga hal yaitu arsitektur aplikasi, arsitektur infrastruktur dan tata kelola IT.

\section{METODOLOGI PENELITIAN}

Pada penelitian ini, langkah-langkah penelitian mengacu pada metodologi dari Enterprise Architecture Planning (EAP). Enterprise Architecture Planning memiliki 7 (tujuh) komponen utama yang menunjukkan tahapan untuk menentukan dan merencanakan implementasi arsitektur sistem informasi. Adapun langkah-langkah dalam penelitian ini dapat dilihat pada gambar 3 berikut: 


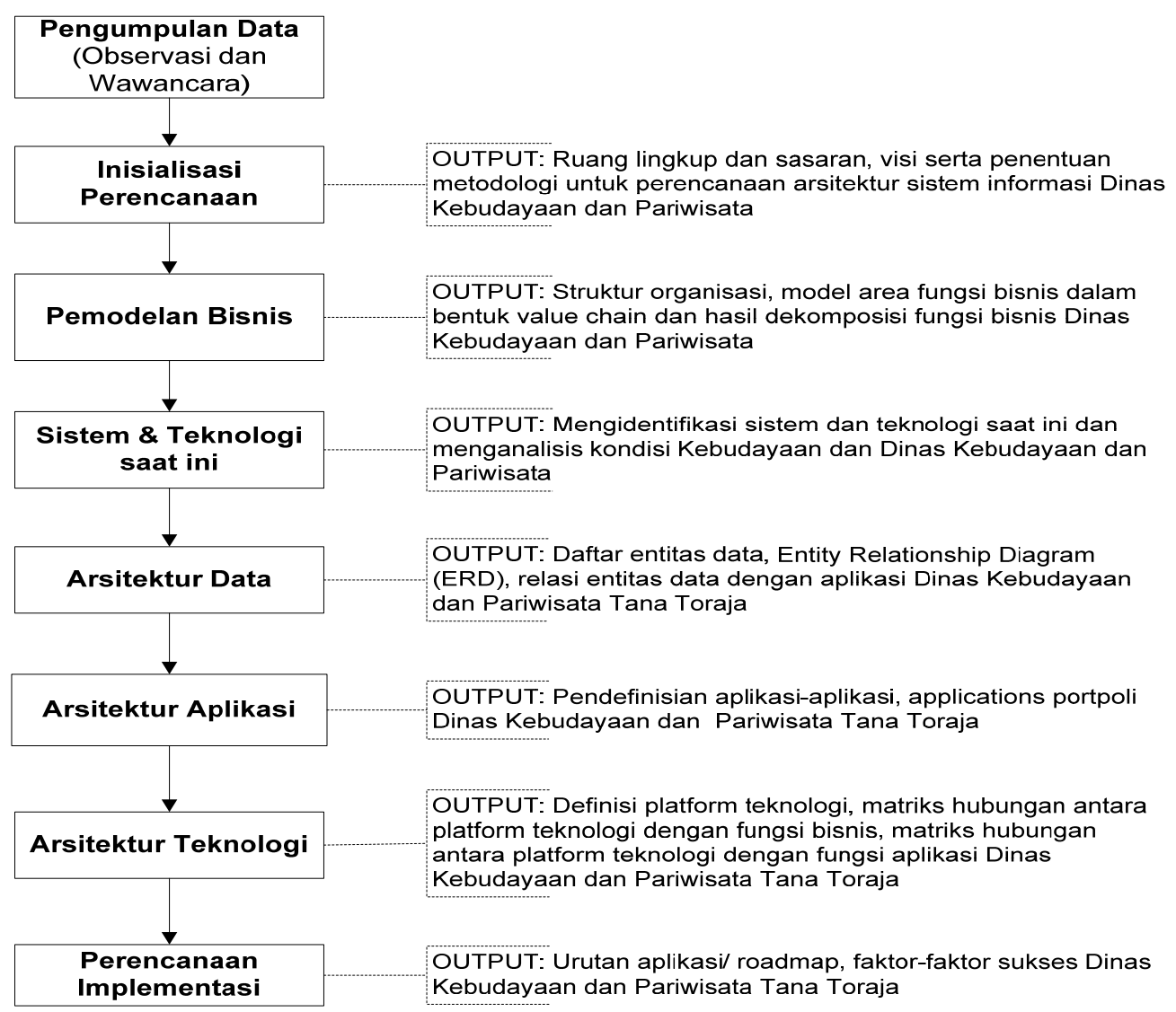

\section{Gambar 3. Langkah-Langkah Penelitian}

\section{HASIL DAN PEMBAHASAN}

\subsection{Identifikasi Area Fungsi Utama}

Pendefinisian area-area fungsi utama di Dinas Kebudayaan dan Pariwisata Tana Toraja menggunakan rantai nilai Michael Porter seperti yang diuraikan pada Gambar 4. Dalam gambar tersebut fungsi bisnis dikelompokan menjadi dua yaitu primary activities dan support activities.

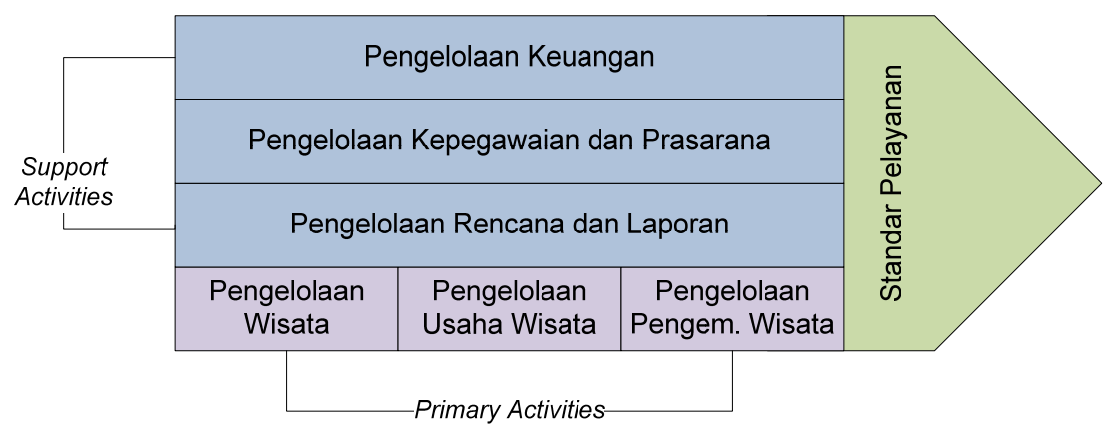

Gambar 4. Rantai Nilai Dinas Kebudayaan dan Pariwisata Tana Toraja

\subsection{Kandidat Entitas Data}

Tujuan dari tahapan ini adalah untuk mendefinisikan semua entitas-entitas data potensial yang diperlukan untuk mendukung bisnis. 


\section{Tabel 2. Entitas Data}

\begin{tabular}{|c|c|}
\hline Entitas Bisnis & Entitas Data \\
\hline \multirow{6}{*}{$\begin{array}{l}\text { Pengelolaan } \\
\text { Kebudayaan }\end{array}$} & 1. Kesenian \\
\hline & 2. Adat Budaya \\
\hline & 3. Promosi \\
\hline & 1. Perizinan_Wisata \\
\hline & 2. Tempat_ $\overline{\mathrm{W}}$ isata \\
\hline & 3. Event \\
\hline Pengelolaan Usaha & 4. Pusat_Souvenir \\
\hline \multirow[t]{5}{*}{ Wisata } & 5. Tempat_Ibadah \\
\hline & 6. Penginapan \\
\hline & 7. Rumah_Makan \\
\hline & 8. Rental $^{-}$ \\
\hline & 1. Tempat_Wisata \\
\hline \multirow{5}{*}{$\begin{array}{l}\text { Pengelolaan } \\
\text { Pengembangan Wisata }\end{array}$} & 2. Event \\
\hline & 3. Promosi \\
\hline & 4. Jadwal_PSW \\
\hline & 5. Jadwal_PSB \\
\hline & 1. Kegiatan_Dinas \\
\hline \multirow{4}{*}{ Pengelolaan Keuangan } & 2. Anggaran \\
\hline & 3. Pencairan_Anggaran \\
\hline & 4. Laporan_K̄euangan \\
\hline & 1. Surat_Menyurat \\
\hline Pengelolaan & 2. Pegawai \\
\hline Kepegawaian dan & 3. Gaji_Pegawai \\
\hline \multirow[t]{2}{*}{ Prasarana } & 4. Kinerja_Pegawai \\
\hline & 5. Aset \\
\hline \multirow{4}{*}{$\begin{array}{l}\text { Pengelolaan } \\
\text { Perencanaan \& } \\
\text { Laporan }\end{array}$} & 1. Anggaran \\
\hline & 2. Evaluasi_Anggaran \\
\hline & 3. Kegiatan_Dinas \\
\hline & 4. Laporan Kegiatan \\
\hline
\end{tabular}

\subsection{Relasi Entitas}

Tahap ini bertujuan menggambarkan masing-masing entitas yang terdapat dalam arsitektur data dan menyediakan ilustrasi secara grafis mengenai inter-relasi diantaranya. Adapun hasil relasi antara entitas dapat dilihat pada gambar 6, gambar 7, gambar 8, gambar 9, dan gambar 10 .

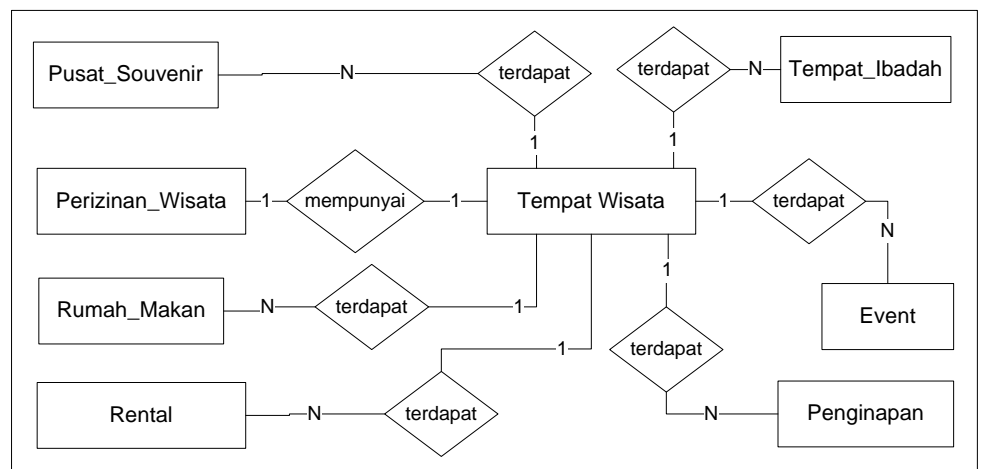

Gambar 5. Relasi Entitas Pengelolaan Usaha Wisata

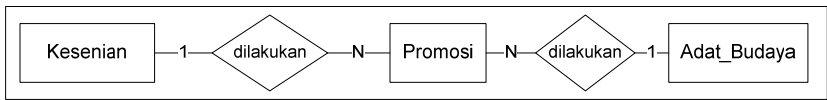

Gambar 6. Relasi Entitas Pengelolaan Kebudayaan 


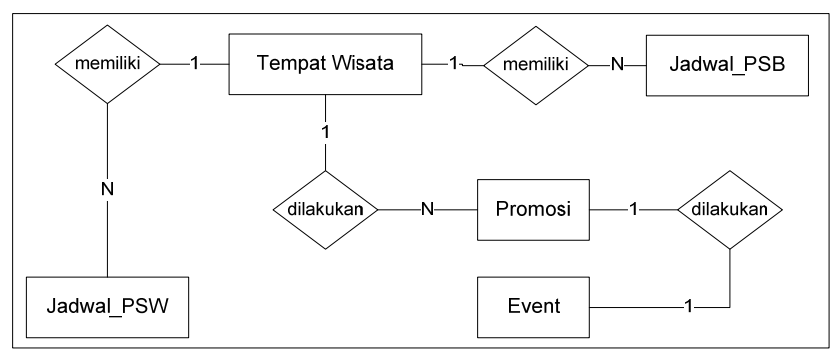

Gambar 7. Relasi Entitas Pengelolaan Pengembangan Wisata

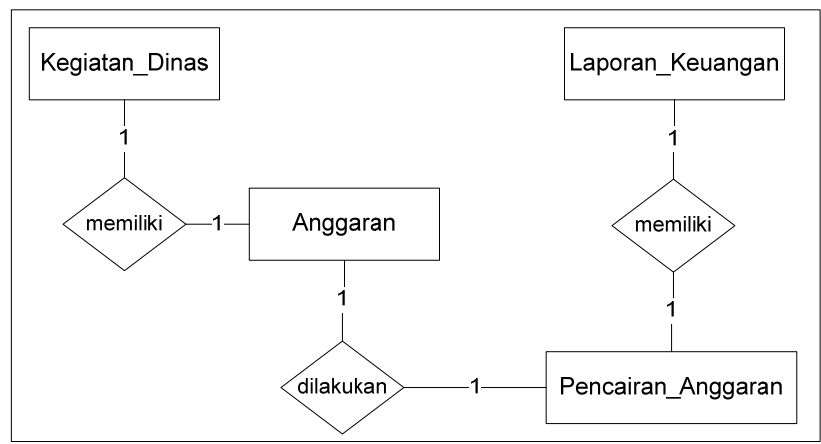

Gambar 8. Relasi Entitas Pengelolaan Keuangan

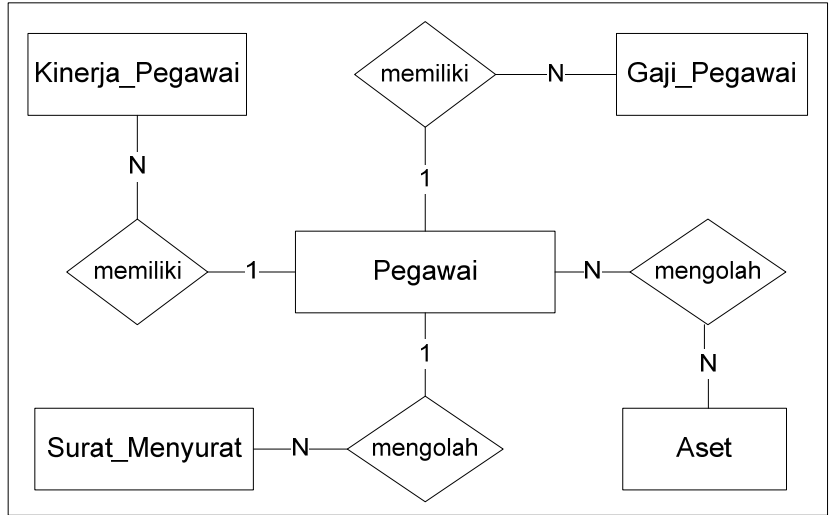

Gambar 9. Relasi Entitas Pengelolaan Kepegawaian dan Prasarana

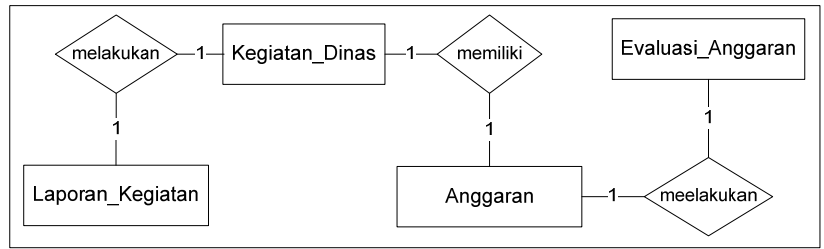

Gambar 10. Relasi Entitas Pengelolaan Rencana dan Pelaporan

\subsection{Kandidat Aplikasi}

Tahap ini bertujuan untuk mengidentifikasi aplikasi-aplikasi yang diperlukan untuk mengelola data dan mendukung bisnis. 
Tabel 3. Kandidat Aplikasi

\begin{tabular}{|c|c|c|c|}
\hline No. & Proses Bisnis & $\begin{array}{c}\text { Kode } \\
\text { Aplikasi }\end{array}$ & Kandidat Aplikasi \\
\hline 1. & Pengelolaan Kebudayaan & APK_ 1 & \\
\hline 2. & Pengelolaan Usaha Wisata & & Website Dinas Pariwisata \\
\hline 3. & Pengelolaan Pengembangan Wisata & & \\
\hline 4. & Pengelolaan Keuangan & APK_2 & $\begin{array}{c}\text { Aplikasi Keuangan Dinas } \\
\text { Pariwisata }\end{array}$ \\
\hline 5. & $\begin{array}{l}\text { Pengelolaan Kepegawaian dan } \\
\text { Prasarana }\end{array}$ & APK_3 & $\begin{array}{c}\text { Aplikasi HRD Dinas } \\
\text { Pariwisata }\end{array}$ \\
\hline 6. & Pengelolaan Perencanaan \& Laporan & APK_ 4 & $\begin{array}{l}\text { Aplikasi Pengawasan dan } \\
\text { Evaluasi Dinas Pariwisata }\end{array}$ \\
\hline
\end{tabular}

\subsection{Relasi Kandidat Aplikasi Dengan Proses Bisnis}

Tahap ini bertujuan untuk mengidentifikasikan fungsi-fungsi bisnis yang secara langsung didukung atau dilakukan oleh aplikasi.

Tabel 4. Relasi Aplikasi dengan Proses Bisnis

\begin{tabular}{|c|c|c|c|c|}
\hline \multirow[b]{2}{*}{ Proses Bisnis } & & & & \\
\hline & 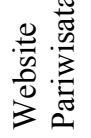 & 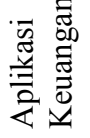 & 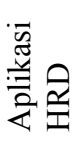 & 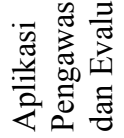 \\
\hline Pengelolaan Kebudayaan & $\mathrm{C}$ & & & \\
\hline Pengelolaan Usaha Pariwisata & $\mathrm{C}$ & & & \\
\hline Pengelolaan Pengembangan Pariwisata & $\mathrm{C}$ & & & \\
\hline Pengelolaan Keuangan & & $\mathrm{C}$ & & \\
\hline Pengelolaan Kepegawaian dan Prasarana & & & $\mathrm{C}$ & \\
\hline Pengelolaan Rencana dan Laporan & & $\mathrm{U}$ & & $\mathrm{C}$ \\
\hline
\end{tabular}

Ket $: \mathrm{C}=$ Create, $\mathrm{U}=$ Use

\subsection{Dekomposisi Kandidat Aplikasi}

Bentuk hirarki analisis Four Stage Life Cycle fitur aplikasi adalah sebagai berikut:

1) Website Dinas Pariwisata;

a. Pengelolaan Kebudayaan;

1. Pendataan Kesenian (Input, Update, Delete, View);

2. Pendataan Adat dan Budaya (Input, Update, Delete, View);

b. Pengelolaan Usaha Pariwisata;

1. Pendataan Izin Wisata (Input, Update, Delete, View);

2. Pendataan Tempat Wisata (Input, Update, Delete, View);

3. Pembuatan Jadwal Event (Input, Update, Delete, View);

4. Pendataan Pusat Souvenir (Input, Update, Delete, View);

5. Pendataan Tempat Ibadah (Input, Update, Delete, View);

6. Pendataan Penginapan (Input, Update, Delete, View);

7. Pendataan Rumah Makan (Input, Update, Delete, View);

8. Pendataan Tempat Rental (Input, Update, Delete, View);

c. Pengelolaan Pengembangan Pariwisata;

1. Pembuatan Promosi (Input, Update, Delete, View);

2. Pembuatan Jadwal PSW (Input, Update, Delete, View);

3. Pembuatan Jadwal PSB (Input, Update, Delete, View);

2) Aplikasi Keuangan Dinas Pariwisata;

Pengelolaan Keuangan;

a) Pendataan Anggaran (Input, Update, Delete, View); 
b) Pencairan Anggaran (Input, Update, Delete, View);

c) Pembuatan Laporan Keuangan (Filter, View, Download);

3) Aplikasi HRD Dinas Pariwisata;

Pengelolaan Kepegawaian dan Prasarana;

a) Pendataan Surat-Menyurat (Input, Update, Delete, View);

b) Pendataan Pegawai (Input, Update, Delete, View);

c) Pendataan Gaji Pegawai (Input, Update, Delete, View);

d) Penilaian Kinerja Pegawai (Input, Update, Delete, View);

e) Pendataan Aset (Input, Update, Delete, View);

4) Aplikasi Pengawasan dan Evaluasi Dinas Pariwisata;

Pengelolaan Rencana dan Laporan;

a) Pendataan Kegiatan Dinas (Input, Update, Delete, View);

b) Pembuatan Laporan Kegiatan (Filter, View, Download);

c) Evaluasi Kegiatan (Input, Update, Delete, View);

\subsection{Kandidat Aplikasi Berdasarkan Portofolio}

Kandidat aplikasi berdasarkan Aplication Portofolio seperti gambar 11 berikut ini.

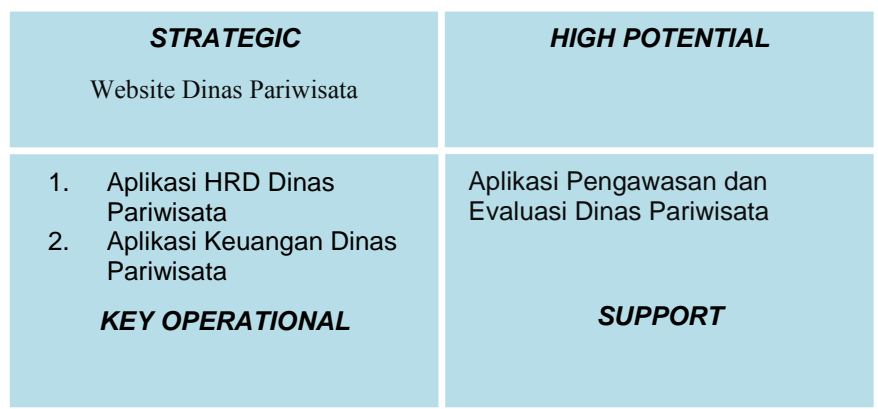

Gambar 11. Kandidat Aplikasi Berdasarkan Aplication Portofolio

\subsection{Defenisi Platform Teknologi}

Tujuan dari tahapan ini adalah menentukan strategi distribusi aplikasi dan data serta mendefinisikan platform teknologi yang akan menjadi lingkungan bagi aplikasi dan data guna mendukung fungsi bisnis seperti pada gambar 12 berikut ini. 


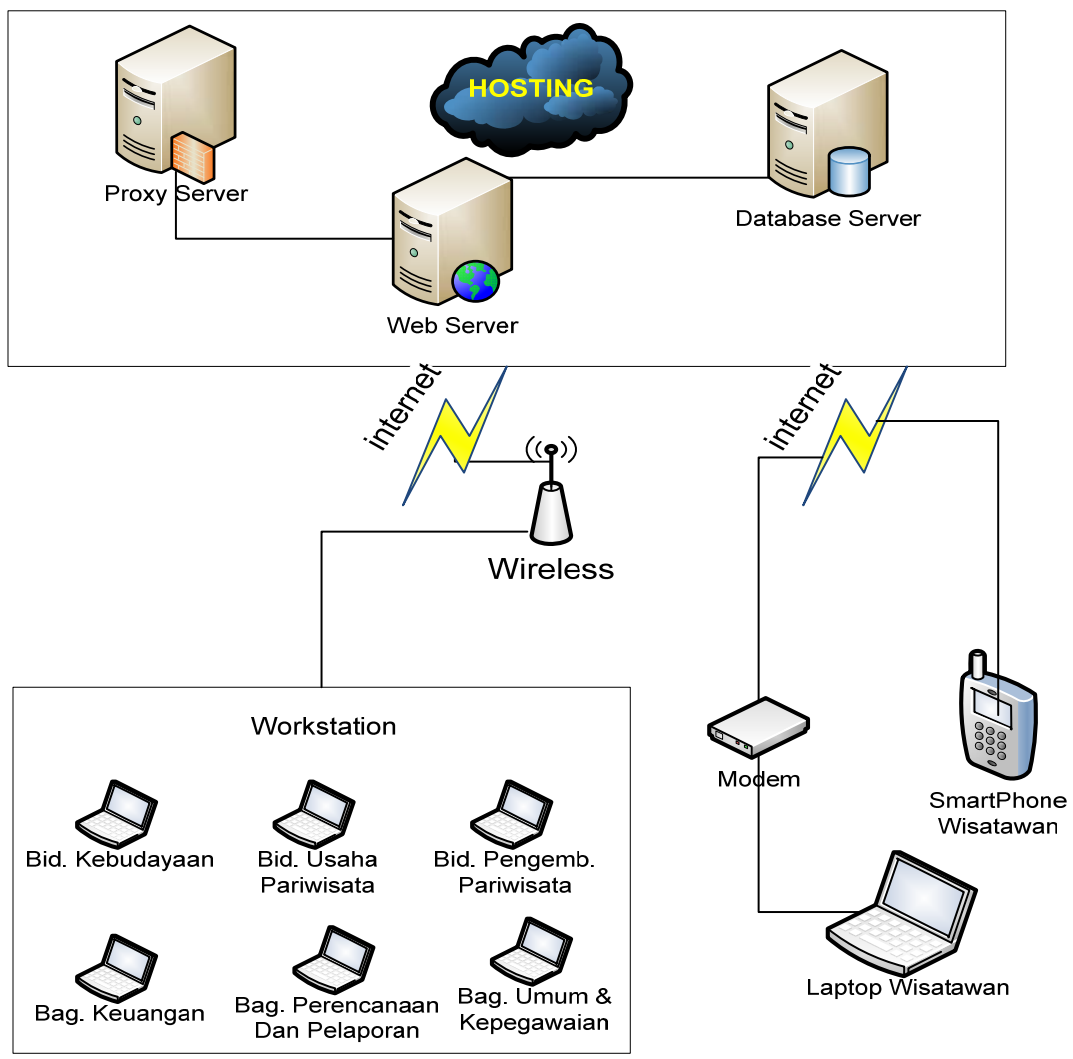

Gambar 12. Arsitektur Teknologi yang diusulkan

\subsection{Relasi Platform Teknologi Dengan Aplikasi}

Tahapan ini dimaksudkan untuk melakukan justifikasi bagi platform teknologi dengan cara merelasikannya dengan aplikasi yang terdefinisi dengan arsitektur aplikasi yang memerlukan teknologi.

Tabel 5. Relasi Platform Teknologi dengan Aplikasi

\begin{tabular}{|c|c|c|c|c|c|c|c|}
\hline \multirow[b]{3}{*}{ Aplikasi } & \multicolumn{4}{|c|}{ Perangkat Lunak } & \multirow{2}{*}{$\begin{array}{c}\begin{array}{c}\text { Networki } \\
\text { ng }\end{array} \\
\text { Network } \\
\text { \& Device }\end{array}$} & \multicolumn{2}{|c|}{ Media } \\
\hline & & $\begin{array}{l}\text { em } \\
\text { rasi }\end{array}$ & $\begin{array}{c}\text { Bahasa } \\
\text { Pemrog } \\
\text { raman }\end{array}$ & $\begin{array}{l}D B \\
M S\end{array}$ & & Pla & orm \\
\hline & 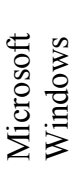 & $\stackrel{\circlearrowright}{. ٍ}$ & 竞 & \begin{tabular}{l}
$\overrightarrow{0}$ \\
\multirow{2}{\Sigma}{}
\end{tabular} & 苞 & $\bigcup$ & कू \\
\hline Website Dinas Pariwisata & $\sqrt{ }$ & $\sqrt{ }$ & $\sqrt{ }$ & $\sqrt{ }$ & $\sqrt{ }$ & $\sqrt{ }$ & $\sqrt{ }$ \\
\hline Aplikasi Keuangan Dinas Pariwisata & $\sqrt{ }$ & $\sqrt{ }$ & $\sqrt{ }$ & $\sqrt{ }$ & $\sqrt{ }$ & $\sqrt{ }$ & \\
\hline Aplikasi HRD Dinas Pariwisata & $\sqrt{ }$ & $\sqrt{ }$ & $\sqrt{ }$ & $\sqrt{ }$ & $\sqrt{ }$ & $\sqrt{ }$ & \\
\hline $\begin{array}{l}\text { Aplikasi Pengawasan dan Evaluasi } \\
\text { Dinas Pariwisata }\end{array}$ & $\sqrt{ }$ & $\sqrt{ }$ & $\sqrt{ }$ & $\sqrt{ }$ & $\sqrt{ }$ & $\sqrt{ }$ & \\
\hline
\end{tabular}




\subsection{Rencana Urutan Implementasi}

Urutan rencana implementasikan dengan model data driven, seperti yang disarankan EAP

Tabel 6. Rencana Urutan Implementasi

\begin{tabular}{cll}
\hline $\begin{array}{c}\text { Nomor } \\
\text { Urut }\end{array}$ & \multicolumn{1}{c}{ Aplikasi } & \multicolumn{1}{c}{ Keterangan } \\
\hline 1 & Website Dinas Pariwisata & Pengembangan Baru \\
2 & Aplikasi HRD Dinas Pariwisata & Pengembangan Baru \\
3 & Aplikasi Keuangan Dinas Pariwisata & Pengembangan Baru \\
4 & Aplikasi Pengawasan dan Evaluasi Dinas Pariwisata & Pengembangan Baru \\
\hline
\end{tabular}

\subsection{Roadmap Rencana Implementasi}

Roadmap untuk pengembangan sistem informasi ini akan dilakukan secara out sourcing seperti pada gambar 13 berikut ini:
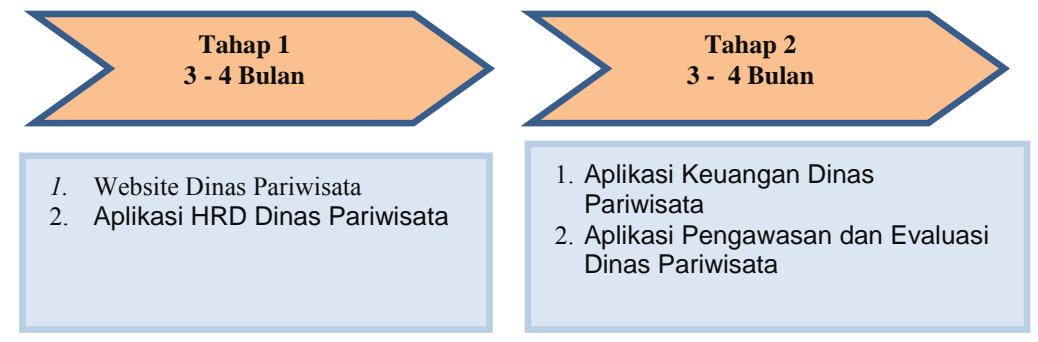

Gambar 13. Roadmap Rencana Implementasi

\section{KESIMPULAN DAN SARAN}

\subsection{Kesimpulan}

Berdasarkan hasil dari tahapan penelitian yang telah dilakukan pada bab sebelumnya, maka penulis mengambil kesimpulan sebagai berikut:

1) Metode $E A P$ dapat digunakan untuk merecanakan arsitektur sistem informasi dinas pariwisata yang berorientasi pada kebutuhan organisasi yang terdiri dari arsitektur data, arsitektur aplikasi dan arsitektur teknologi serta rencana implementasi dari arsitektur yang telah dibuat untuk mendukung aktivitas bisnis demi pencapaian misi dinas pariwisata;

2) Untuk mendukung proses bisnis di Dinas Pariwisata Tana Toraja maka diperlukan system informasi yang didalamnya terdapat beberapa aplikasi yaitu web dinas pariwisata, aplikasi keuangan, aplikasi HRD dan aplikasi pengawasan dan evaluasi;

3) Agar sistem informasi sesuai dengan perkembangan teknologi yang berkembang saat ini maka diusulkan agar aplikasi yang akan dibangun berbasis teknologi jaringan.

\subsection{Saran}

Adapun saran yang dapat penulis sarankan untuk pengembangan maupun pengimplementasian penelitian ini adalah sebagai berikut:

1) Untuk membantu mempercepat implementasi, maka diperlukan komitmen manajemen yang kuat dan konsisten serta keterlibatan secara langsung;

2) Dari hasil perencanaan arsitektur sistem informasi yang telah di lakukan, maka diharapkan untuk dapat dilanjutkan ke tahap berikutnya yaitu perancangan agar implementasi dapat terwujud;

3) Dinas Kebudayaan dan Pariwisata Tana Toraja perlu membentuk sebuah unit khusus yang berkompeten di bidang TI agar implementasi dapat terwujud sesuai dengan yang diharapkan.

\section{DAFTAR PUSTAKA}

[1] Fatansyah.(1999). Sistem Basis Data. Bandung : Informatika. 
[2] Laudon, K C., and Laudon, J P. (2011). Management Information System: Managing the Digital Firm, 12th Edition. New Jersey: Prentice Hall.

[3] Mapaliey, Y.S. (2009). Thesis: Kajian Penurunan Jumlah Wisatawan Di Tana Toraja. Semarang: Universitas Diponegoro.

[4] Osvalds, G. (2001). Definition of Enterprise Architecture-centric Models for the Systems Engineer. TASC. Inc.

[5] Spewak, S. H.(1992). Enterprise Architecture Planning: Developing a Blueprint for Data, Applications, and Technology, John Wiley \& Sons, Inc.

[6] Surendro, K. (2009). Pengembangan Rencana Induk Sistem Informasi. Bandung: Penerbit Informatika.

[7] Porter, Michael E. (1985). Competitive Advantage: Creating and Sustaining Superior Performance. New York: Free Press.

[8] Ward, J., and Peppard, J. (2002). Strategic Planning For Information System. 3rd Edition. Chichester: John Willey \& Sons, Buffins Lane

[9] Zachman, J.A. (1982). "Business System Planning (Information System Planning Guide). International Busniness Machine Corporation”. IBM systems Journal, Vol. 21. 